\title{
Thermophysical measurements on transition-metal tungstates III. Heat capacity of antiferromagnetic manganese tungstate ${ }^{a}$
}

\author{
CHRISTOPHER P. LANDEE ${ }^{b, c}$ and EDGAR F. WESTRUM, Jr. \\ Department of Chemistry, The University of Michigan, Ann Arbor, \\ Michigan 48104, U.S.A.
}

(Received 13 January 1976)

\begin{abstract}
Three anomalies were found during measurements of the heat capacity of manganese tungstate from 4 to $350 \mathrm{~K}$ by adiabatic calorimetry; a small peak at $(6.8 \pm 0.1) \mathrm{K}$, and two large sharp peaks at $(12.57 \pm 0.05) \mathrm{K}$ and $(13.36 \pm 0.05) \mathrm{K}$. The excess entropy associated with the antiferromagnetic transition was estimated by means of calculations which utilized the heat capacity of zinc tungstate to approximate contributions from lattice vibrations and was found in good accord with the value $R \ln 6$. The results between 5 and $11.5 \mathrm{~K}$ obey a power law: $C_{\operatorname{mag}}=A T^{1 \cdot 73}$. The double anomaly is discussed in terms of the super-exchange properties of $\mathrm{MnWO}_{4}$. Selected thermal functions, $C_{p}^{\circ}, S^{\circ}$, and $-\left\{G^{\circ}(T)-H^{\circ}(0)\right\} / T$ are respectively $27.40,31.66$, and $16.10 \mathrm{cal}_{\mathrm{th}} \mathrm{K}^{-1} \mathrm{~mol}^{-1}$ at $T=298.15 \mathrm{~K}$.
\end{abstract}

\section{Introduction}

Manganese tungstate $\left(\mathrm{MnWO}_{4}\right)$ is a member of the isostructural series of first-row ( $\mathrm{Mn}, \mathrm{Fe}, \mathrm{Co}, \mathrm{Ni}$, and $\mathrm{Zn}$ ) transition-metal tungstates of which those members of the series with incomplete $3 \mathrm{~d}$ shells display antiferromagnetic behavior. To supplement the thermophysical properties of the members of the series reported previously, ${ }^{(1-3)}$ the heat capacity of the antiferromagnetic-to-paramagnetic phase transition in $\mathrm{MnWO}_{4}$ is discussed in the present work.

The crystal structures of the $\mathrm{MnWO}_{4}$ compounds are of the $\mathrm{NiWO}_{4}$-type, ${ }^{(4)}$ space group $\mathrm{P} 2 / \mathrm{C}\left(\mathrm{C}_{2 \mathrm{~h}}^{4}\right)$; the lattice parameters increase irregularly along the series. ${ }^{(5)}$ The structure is monoclinic, with two formula units per unit cell and is characterized by zigzag chains of metal-filled oxygen octahedra aligned along the $c$-axis. The crystal structure of the $\mathrm{NiWO}_{4}$-type tungstates is shown in figure 1 ; but the magnetic structure of $\mathrm{MnWO}_{4}$ is unique among these tungstates. Ferrous, cobalt, and nickel

a Supported by the National Science Foundation.

- Abstracted in part from a dissertation submitted in partial fulfillment of the requirements for the Ph.D. degree from the Horace H. Rackham School of Graduate Studies at the University of Michigan.

- Present address: Department of Chemistry, Washington State University, Pullman, Washington 99163, U.S.A. 


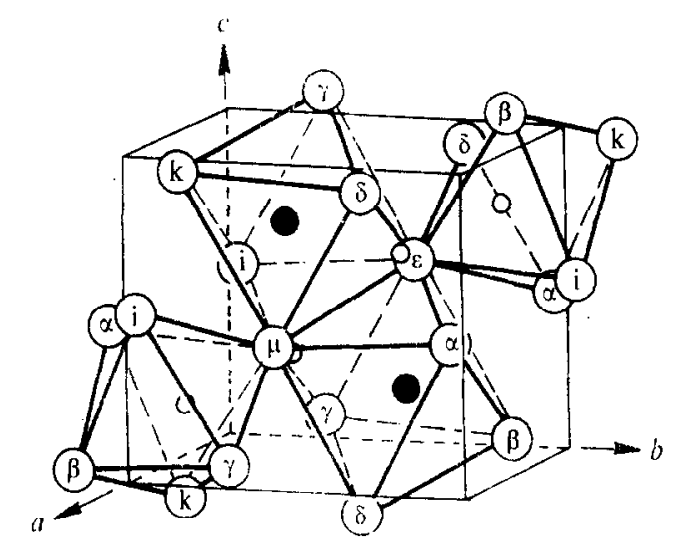

FIGURE 1. Crystallographic unit cell of the $\mathrm{NiWO}_{4}$-type tungstates. Solid circles are metal atoms, small open circles are tungsten atoms, and large open circles are oxygen atoms. After Ölkü.(6)

tungstates possess a common magnetic structure in which the magnetic moments are ferromagnetically aligned within the chains in the $a c$-plane and antiferromagnetically coupled to adjacent layers. ${ }^{(6,7)}$ The magnetic unit cell for these compounds is double the crystallographic unit cell along the $a$-axis (see figure 2). However, for $\mathrm{MnWO}_{4}$ the magnetic unit cell consists of 16 crystallographic unit cells, for Dachs, Weitzel, and Stoll ${ }^{(8)}$ concluded that the magnetic unit cell of $\mathrm{MnWO}_{4}$ is

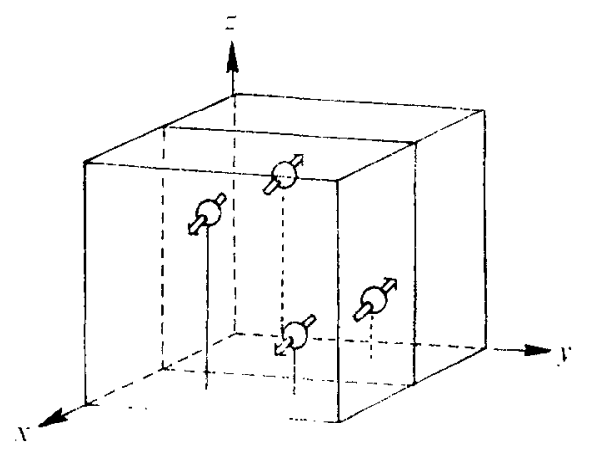

FIGURE 2. Magnetic structure of ferrous, nickel, and cobalt tungstates. After Ülkü..(6)

twice as large in the $b$ - and $c$-directions and four times larger in the $a$-direction as for the other members. The magnetic space group is $A_{c} 2 / a$. Two neighboring crystallographic unit cells in the $a$-direction contain all magnetic structural information (see figure 3). The magnetic structure has been analyzed by Dachs ${ }^{(9)}$ who attributes the structure to a strong antiferromagnetic coupling along the $c$-axis, i.e. along the chains. Magnetic-susceptibility measurements by several investigators ${ }^{(10-12)}$ indicated antiferromagnetic behavior with a Néel temperature near $15 \mathrm{~K}$ and a magnetic moment consistent with an $s=5 / 2$ magnetic ion. 


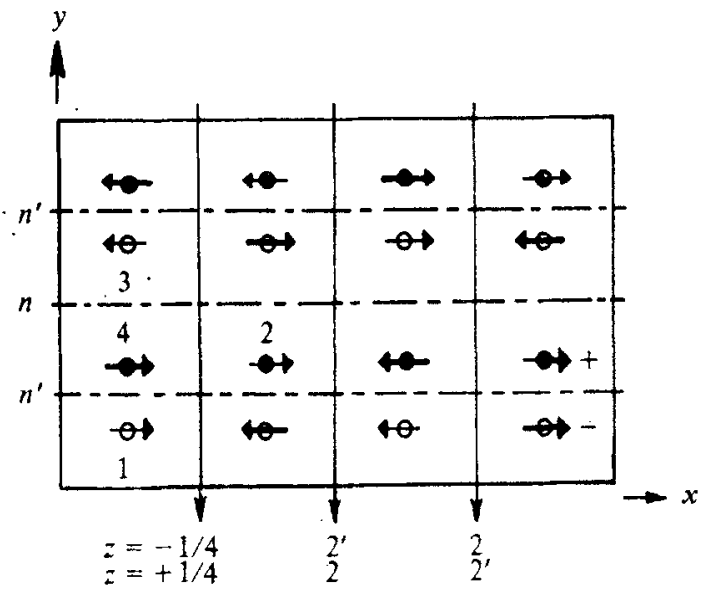

FIGURE 3. Magnetic structure of manganese tungstate. ${ }^{(8)}$ Only half the magnetic cell is shown. The second half lies over the layer shown with spin moments in antiparallel array. The $x$-axis shown does not coincide with the crystallographic $x$-axis. After Dachs. ${ }^{(9)}$

\section{Experimental}

\section{SAMPLE PREPARATION AND CHARACTERIZATION}

The powder sample of $\mathrm{MnWO}_{4}$ purchased from Rocky Mountain Research had a claimed purity of 99 mass per cent. The dark-brown material was initially amorphous but after compression into a pellet and firing in air at $1370 \mathrm{~K}$ for $1 \mathrm{~d}$, sharp X-ray reflexions were obtained. The calorimetric sample was prepared by pressing a pellet, scraping the top and bottom, and firing in a platinum crucible for $5 \mathrm{~d}$ at $1300 \mathrm{~K}$. The outer surface was scraped off after firing and the pellet broken into fragments small enough to fit into the calorimeter. X-Ray diffraction analyses showed no impurity lines. The lattice parameters derived for this sample are in good agreement with those found by other investigators (see table 1) ${ }^{(13-15)}$ The details of the X-ray analysis are reported in a supplementary document. ${ }^{(16)}$

TABLE 1. Derived lattice parameters of manganese tungstate

\begin{tabular}{|c|c|c|c|c|}
\hline$a / \mathrm{nm}$ & $b / \mathrm{nm}$ & $c / n m$ & $\beta$ & Reference \\
\hline $\begin{array}{c}0.485 \pm 0.001 \\
0.4829 \pm 0.0004 \\
0.4834 \pm 0.0004 \\
0.4829 \pm 0.0001 \\
0.4832 \pm 0.0003\end{array}$ & $\begin{array}{c}0.577 \pm 0.001 \\
0.5759 \pm 0.0004 \\
0.5758 \pm 0.0004 \\
0.5758 \pm 0.0001 \\
0.5758 \pm 0.0003\end{array}$ & $\begin{array}{c}0.498 \pm 0.001 \\
0.4998 \pm 0.0004 \\
0.4999 \pm 0.0004 \\
0.4996 \pm 0.0001 \\
0.4997 \pm 0.0002\end{array}$ & $\begin{array}{l}90.88^{\circ} \\
91.16^{\circ} \\
91.18^{\circ} \\
(91.15 \pm 0.02)^{\circ} \\
(91.16 \pm 0.04)^{\circ}\end{array}$ & $\begin{array}{l}\text { Broch }^{(13)} \\
\text { Swanson et al. } .^{(14)} \\
\text { Sasaki }{ }^{(15)} \\
\text { Sleight(5) } \\
\text { This research } \\
\text { Guinier, Cu K } \alpha\end{array}$ \\
\hline
\end{tabular}

Commercial chemical analyses ${ }^{(17)}$ involved decomposition of the sample in an acid mixture and the determination of the mass percentage of manganese by EDTA titration with Erichrome-T as indicator. The tungsten content was determined 
colorimetrically by the procedure of Gottschalk. ${ }^{(18)}$ The analyses showed $(100.3 \pm 0.4)$ and $(100.0 \pm 0.3)$ per cent of the theoretical manganese and tungsten content. An atomic absorption analysis for iron revealed a mass fraction of $4 \times 10^{-5}$.

\section{HEAT-CAPACITY MEASUREMENTS}

Heat-capacity measurements were made in the Mark II adiabatic cryostat. ${ }^{(19)}$ The calorimeter, laboratory designation W-52, was a gold-plated OFHC-copper can of internal volume $59.11 \mathrm{~cm}^{3}$. A sample of $84.883 \mathrm{~g}$ was loaded into the calorimeter along with 61 Torr of helium exchange gas. $\dagger$ A molar mass of $302.7856 \mathrm{~g} \mathrm{~mol}^{-1}$ was used in converting the results to molar quantities. The density of $7.23 \mathrm{~g} \mathrm{~cm}^{-3}$ used in buoyancy corrections was taken from Swanson et al. ${ }^{(14)}$ The results were taken against the IPTS-48 temperature scale.

\section{Results and discussion}

\section{THERMOPHYSICAL FUNCTIONS}

The heat capacities of $\mathrm{MnWO}_{4}$ are given in table 2 in chronological sequence so that temperature increments usually can be approximately deduced from the adjacent mean temperatures. Series of points for which no temperature increments are given

TABLE 2. Heat capacity of manganese tungstate $\left(\mathrm{cal}_{\mathrm{tb}}-4.184 \mathrm{~J}\right)$

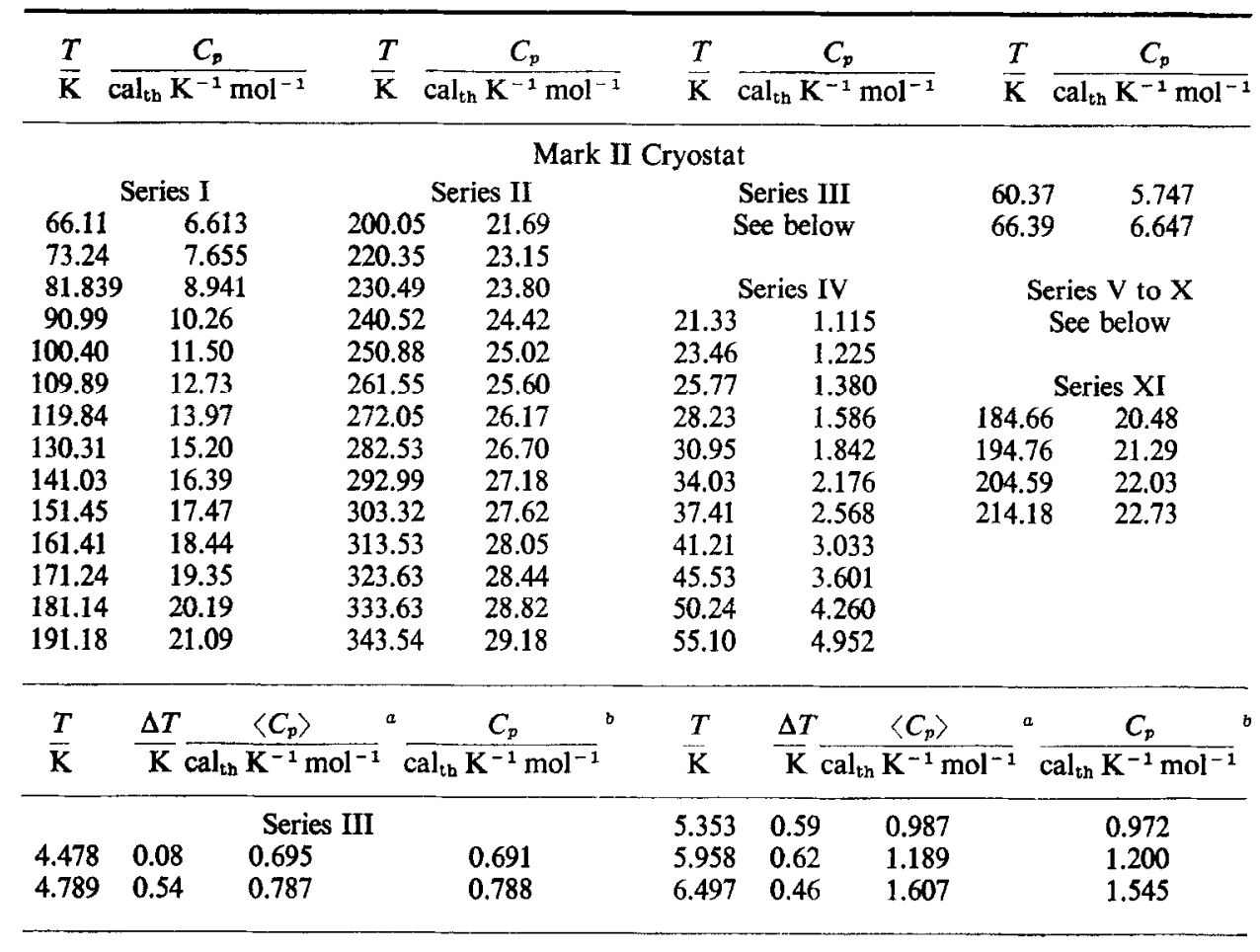

$\dagger$ Throughout this paper Torr $=(101.325 / 760) \mathrm{kPa} ; \mathrm{cal}_{\mathrm{th}}=4.184 \mathrm{~J}$. 
TABLE 2-continued

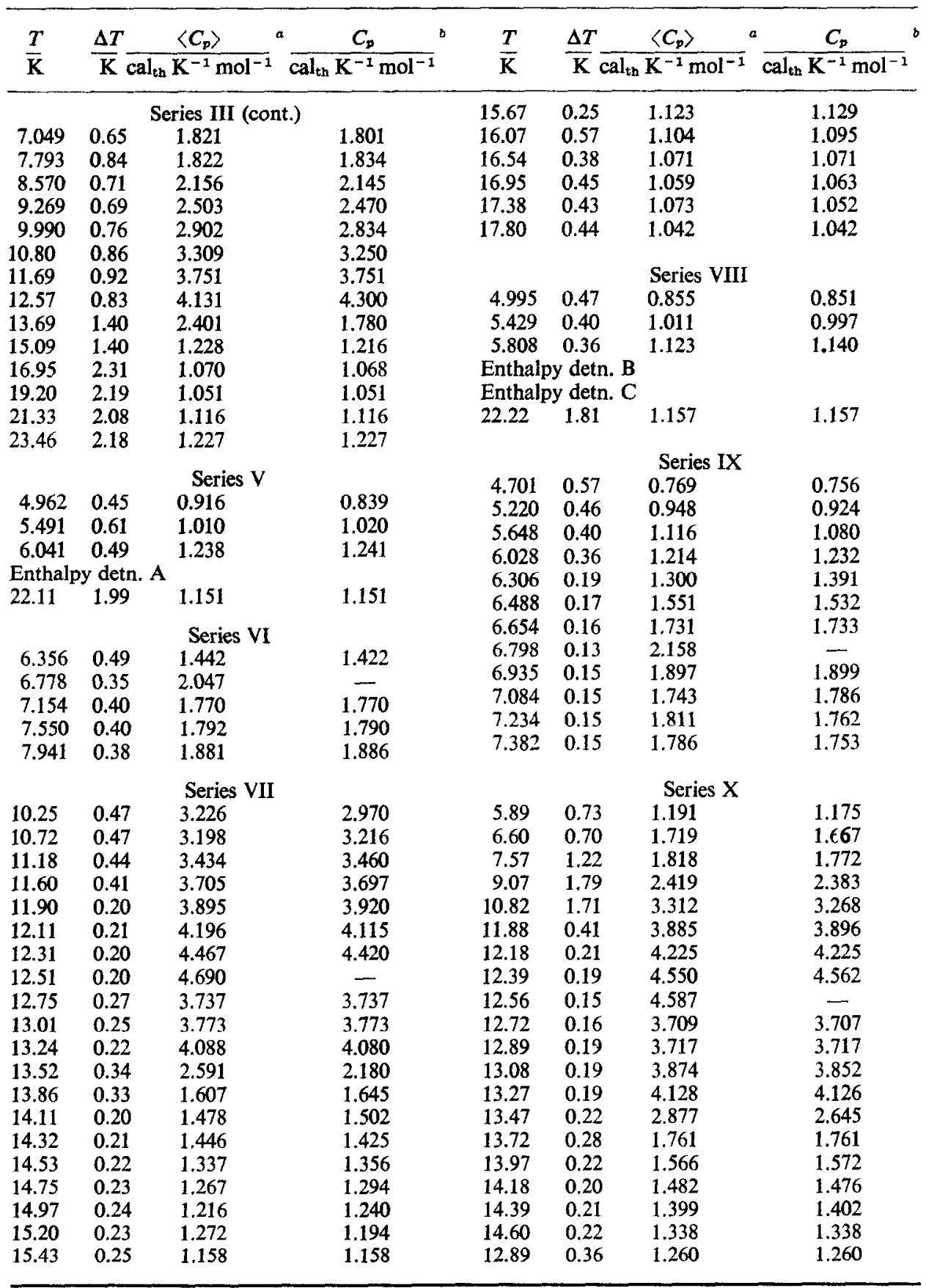

a The symbol $\left\langle C_{p}\right\rangle$ represents a mean value of the heat capacity as calculated directly from finite $\Delta H / \Delta T$ without curvature correction.

${ }^{\circ}$ The symbol $C_{p}$ in columns adjacent to $\left\langle C_{p}\right\rangle$ represents the value of the heat capacity read from the smoothed curve at temperature $T$. Elsewhere in the table it represents $C_{p}$ analytically corrected for curvature. 
have had slight adjustment made for curvature. The enthalpy determinations have been summarized in table 3 .

The molar experimental heat capacies in non-transition regions were curvature corrected and fitted to polynomials in reduced temperature by the method of least squares and integrated to yield values of the thermodynamic functions at selected

TABLE 3. Enthalpy determinations for manganese tungstate, Mark II cryostat $\left(\mathrm{cal}_{\mathrm{th}}=4.184 \mathrm{~J}\right)$

\begin{tabular}{|c|c|c|c|c|}
\hline Designation & $\frac{T_{1}}{\mathrm{~K}}$ & $\frac{T_{2}}{\mathrm{~K}}$ & $\frac{H\left(T_{1}\right)-H\left(T_{2}\right)}{\mathrm{cal}_{\text {th }} \mathrm{mol}^{-1}}$ & $\frac{H(8.5 \mathrm{~K})-H(6 \mathrm{~K})}{\mathrm{cal}_{\mathrm{th}} \mathrm{mol}^{-1}}$ \\
\hline \multicolumn{5}{|c|}{ I. $6.8 \mathrm{~K}$ peak } \\
\hline $\begin{array}{l}\text { B (Series VIII) } \\
\text { Series VI } \\
\text { Series IX } \\
\text { Series X }\end{array}$ & $\begin{array}{l}5.99 \\
6.11 \\
6.21 \\
6.26\end{array}$ & $\begin{array}{l}8.75 \\
8.13 \\
7.46 \\
8.17\end{array}$ & $\begin{array}{l}4.92 \\
3.56 \\
2.15 \\
3.42\end{array}$ & $\begin{array}{l}4.37 \\
4.45 \\
4.41 \\
4.41\end{array}$ \\
\hline & & & \multicolumn{2}{|r|}{ Mean: $\quad(4.41 \pm 0.55)$} \\
\hline Designation & $\frac{T_{1}}{K}$ & $\frac{T_{2}}{\mathrm{~K}}$ & $\frac{H\left(T_{1}\right)-H\left(T_{2}\right)}{\mathrm{cal}_{\mathrm{th}} \mathrm{mol}^{-1}}$ & $\frac{H(20 \mathrm{~K})-H(8 \mathrm{~K})}{\mathrm{cal}_{\mathrm{tn}} \mathrm{mol}^{-1}}$ \\
\hline \multicolumn{5}{|c|}{ II. Double peak } \\
\hline $\begin{array}{l}\text { A } \\
\text { C } \\
\text { Series III } \\
\text { Series VIII } \\
\text { Series X }\end{array}$ & $\begin{array}{r}6.29 \\
8.75 \\
8.21 \\
10.02 \\
8.17\end{array}$ & $\begin{array}{l}21.13 \\
21.31 \\
20.29 \\
18.02 \\
15.07\end{array}$ & $\begin{array}{l}29.43 \\
25.05 \\
25.07 \\
18.55 \\
19.65\end{array}$ & $\begin{array}{l}25.16 \\
25.16 \\
25.17 \\
25.23 \\
25.30\end{array}$ \\
\hline \multicolumn{5}{|r|}{ Mean: $\quad(25.21 \pm 0.13)$} \\
\hline
\end{tabular}

temperature intervals. Within the transition region the thermal functions are based upon numerical integration of heat capacity points mapped on to large-scale plots. Values thus obtained are presented in table 4. Entropy and enthalpy increments below the lowest temperatures of measurement were obtained by extrapolation. They are given in parentheses at the lowest temperature. The procedure involved fitting the heat capacity from 4 to $11.5 \mathrm{~K}$ with an exponential curve which was then extrapolated down to $T \rightarrow 0$ and integrated. This extrapolated entropy is about 1 per cent of the total entropy at $298.15 \mathrm{~K}$ and as will be seen later, about 8 per cent of the total magnetic entropy.

\section{EVALUATION OF MAGNETIC ENTROPY}

The experimentally measured heat capacity consists of contributions from the lattice vibrations as well as from the magnetic interactions. An estimate of the lattice contributions is, therefore, necessary to resolve the magnetic heat capacity.

The heat capacity of $\mathrm{ZnWO}_{4}{ }^{(2)}$ serves as an approximation to the lattice contribution for $\mathrm{MnWO}_{4}$. The zinc compound is isostructural and from the melting temperature together with the Lindemann relation, would seem to possess chemical 
TABLE 4. Thermal functions of manganese tungstate

$\left(\mathrm{cal}_{\mathrm{en}}=4.184 \mathrm{~J}\right)$

\begin{tabular}{|c|c|c|c|c|}
\hline$\frac{T}{\mathrm{~K}}$ & $\frac{C_{p}}{\mathrm{Cal}_{\mathrm{th}} \mathrm{K}^{-1} \mathrm{~mol}^{-1}}$ & $\frac{S^{\circ}(T)-S^{\circ}(0)}{\mathrm{cal}_{\mathrm{th}} \mathrm{K}^{-1} \mathrm{~mol}^{-1}}$ & $\frac{H^{\circ}(T)-H^{\circ}(0)}{\mathrm{cal}_{\mathrm{th}} \mathrm{mol}^{-1}}$ & $\frac{-\left\{G^{\circ}(T)-H^{\circ}(0)\right\} / T}{\mathrm{cal}_{\mathrm{th}} \mathrm{K}^{-1} \mathrm{~mol}^{-1}}$ \\
\hline 5 & 0.850 & $(0.496)^{a}$ & $(1.57)^{a}$ & - \\
\hline 10 & 2.840 & 1.692 & 10.74 & - \\
\hline 15 & 1.232 & 3.180 & 27.22 & - \\
\hline 20 & 1.075 & 3.491 & 32.61 & - \\
\hline 25 & 1.326 & 3.660 & 36.35 & - \\
\hline 30 & 1.749 & 3.789 & 44.705 & 2.299 \\
\hline 35 & 2.284 & 4.097 & 54.76 & 2.533 \\
\hline 40 & 2.884 & 4.441 & 67.66 & 2.750 \\
\hline 45 & 3.530 & 4.818 & 83.68 & 2.958 \\
\hline 50 & 4.218 & 5.225 & 103.03 & 3.164 \\
\hline 60 & 5.692 & 6.123 & 152.51 & 3.581 \\
\hline 70 & 7.183 & 7.113 & 216.91 & 4.014 \\
\hline 80 & 8.675 & 8.169 & 296.16 & 4.467 \\
\hline 90 & 10.110 & 9.275 & 390.19 & 4.939 \\
\hline 100 & 11.463 & 10.410 & 498.11 & 5.429 \\
\hline 110 & 12.754 & 11.564 & 619.2 & 5.935 \\
\hline 120 & 13.988 & 12.727 & 753.0 & 6.452 \\
\hline 130 & 15.16 & 13.893 & 898.8 & 6.980 \\
\hline 140 & 16.27 & 15.06 & 1056.0 & 7.515 \\
\hline 150 & 17.32 & 16.22 & 1224.0 & 8.057 \\
\hline 160 & 18.31 & 17.37 & 1402.2 & 8.603 \\
\hline 170 & 19.23 & 18.50 & 1590.0 & 9.152 \\
\hline 180 & 20.10 & 19.63 & 1786.7 & 9.703 \\
\hline 190 & 20.92 & 20.74 & 1991.8 & 10.254 \\
\hline 200 & 21.69 & 21.83 & 2204.9 & 10.806 \\
\hline 210 & 22.42 & 22.91 & 2425.5 & 11.356 \\
\hline 220 & 23.11 & 23.97 & 2653.2 & 11.906 \\
\hline 230 & 23.77 & 25.01 & 2887.6 & 12.453 \\
\hline 240 & 24.39 & 26.03 & 3128.4 & 12.997 \\
\hline 250 & 24.98 & 27.04 & 3375.3 & 13.539 \\
\hline 260 & 25.53 & 28.03 & 3627.9 & 14.077 \\
\hline 270 & 26.06 & 29.00 & 3885.9 & 14.612 \\
\hline 280 & 26.56 & 29.96 & 4149.0 & 15.14 \\
\hline 290 & 27.03 & 30.90 & 4417.0 & 15.67 \\
\hline 300 & 27.48 & 31.83 & 4689.6 & 16.19 \\
\hline 310 & 27.90 & 32.73 & 4966.6 & 16.71 \\
\hline 320 & 28.31 & 33.63 & 5248 & 17.23 \\
\hline 330 & 28.69 & 34.50 & 5533 & 17.74 \\
\hline 340 & 29.05 & 35.36 & 5821 & 18.24 \\
\hline 350 & 29.40 & 36.21 & 6114 & 18.74 \\
\hline 273.15 & 26.22 & 29.31 & 3968.2 & 14.780 \\
\hline 298.15 & 27.40 & 31.66 & 4638.8 & 16.10 \\
\hline
\end{tabular}

${ }^{8}$ Based on $C=0.05 \mathrm{cal}_{\mathrm{th}} \mathrm{K}^{-1} \mathrm{~mol}^{-1}(T / \mathrm{K})^{1.723}$ see text. 
bond strengths similar to those found in the manganese tungstate. Experimentally, the trends of the heat capacities are very similar; the zinc tungstate has a heat capacity only several tenths of a per cent larger than that of the manganese compound between 150 and $350 \mathrm{~K}$.

The $\Theta_{\text {Debye }}$ 's were calculated for both the $\mathrm{ZnWO}_{4}$ and $\mathrm{MnWO}_{4}$ results and the ratios $\Theta\left(\mathrm{MnWO}_{4}\right) / \Theta\left(\mathrm{ZnWO}_{4}\right)$ plotted as a function of temperature. From 120 to $350 \mathrm{~K}$, this ratio is linear and nearly unity. The ratio rises as the temperature drops below $120 \mathrm{~K}$ and then drops sharply near $65 \mathrm{~K}$ as the magnetic heat capacity affects $\Theta\left(\mathrm{MnWO}_{4}\right)$. Harmonic theory predicts $\Theta\left(\mathrm{MnWO}_{4}\right) / \Theta\left(\mathrm{ZnWO}_{4}\right) \approx\left(M_{\mathrm{Zn}} / M_{\mathrm{Mn}}\right)^{1 / 2}=$ 1.091 in which $M$ 's represent atomic masses; this value was chosen as the lowtemperature limit of the ratio and the curve interpolated smoothly between the lowtemperature limit and the experimental ratios above $65 \mathrm{~K}$. The interpolated $\Theta\left(\mathrm{MnWO}_{4}\right)$ 's were then calculated from the ratio curve and the experimentally known $\Theta\left(\mathrm{ZnWO}_{4}\right)$ 's. The thus defined lattice heat capacities of $\mathrm{MnWO}_{4}$ were then calculated.

The ionic (rather than the formula) masses were used since the valence force field calculations of Lesne and Caillet ${ }^{(20)}$ showed that $\mathrm{Mn}^{2+}$ ions are but loosely coupled to the rigid oxygen tungsten matrix. Hence, at low temperatures the first-row metals are vibrating independently of the tungstens. Such behavior has been seen in the studies of iron impurities in metal host lattices. ${ }^{(21)}$ When the magnetic entropy was calculated using a lower limit for the $\Theta$-ratios based upon the formula masses, only 85 per cent of the expected magnetic entropy appeared. For these reasons the ionic masses were used.

The low-temperature heat capacities for $\mathrm{MnWO}_{4}$ are presented in figure 4. A small peak appears at $(6.80 \pm 0.1) \mathrm{K}$; the main peak is bifurcated with twin peaks appearing at $(12.57 \pm 0.05) \mathrm{K}$ and $(13.36 \pm 0.05) \mathrm{K}$. The low-temperature values for zinc

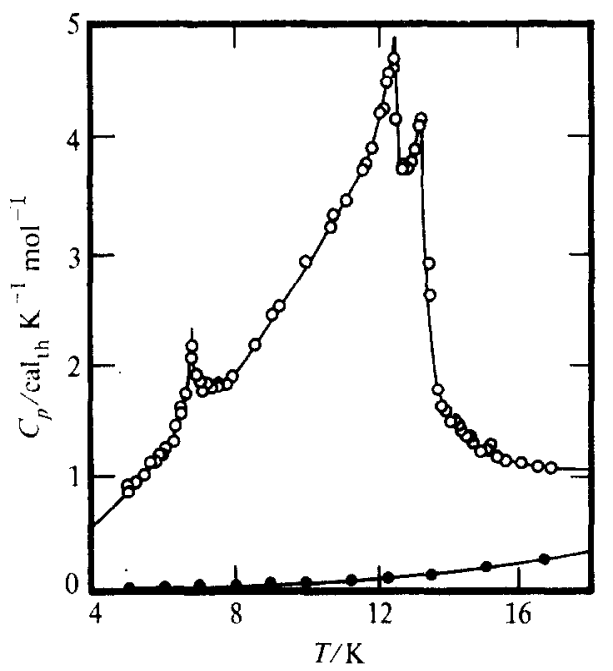

FIGURE 4. The heat-capacity anomaly in $\mathrm{MnWO}_{4}$. Comparison with results for $\mathrm{ZnWO}_{4}$. $\mathrm{O}, \mathrm{MnWO}_{4} ; \bullet, \mathrm{ZnWO}_{4}$. 
tungstate are also shown. The curve drawn through the $\mathrm{ZnWO}_{4}$ results represents the estimated lattice contribution of $\mathrm{MnWO}_{4}$ as calculated above.

The magnetic heat capacity is the difference between the total and estimated lattice heat capacities. The magnetic enthalpy and entropy were calculated by integration of the heat capacity as $44.4 \mathrm{cal}_{\mathrm{th}} \mathrm{mol}^{-1}$ and $3.60 \mathrm{cal}_{\mathrm{th}} \mathrm{K}^{-1} \mathrm{~mol}^{-1}$, respectively. The magnetic entropy shown in figure 5 as a function of temperature is within 1 per cent

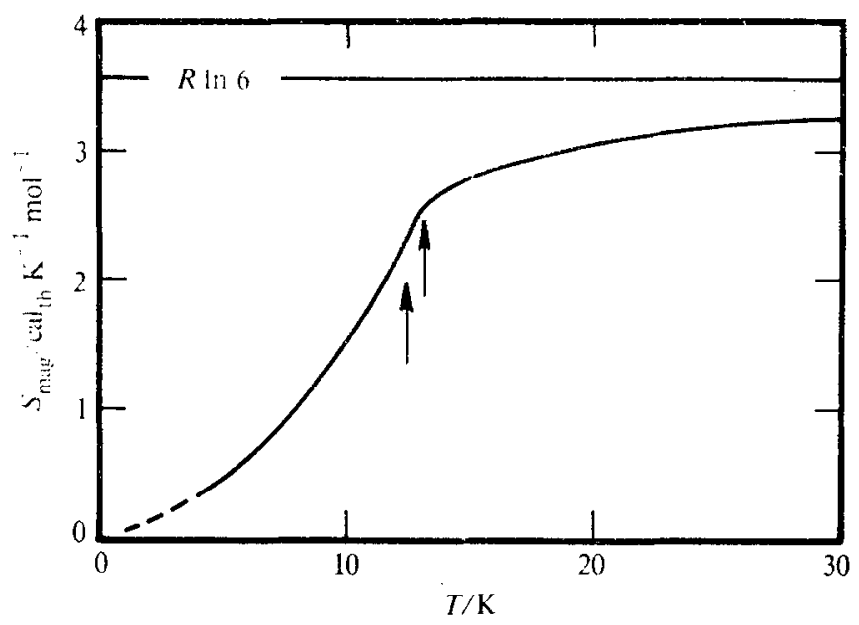

FIGURE 5. The magnetic entropy of $\mathrm{MnWO}_{4}$. The arrows indicate the heat-capacity peaks identified as Néel temperatures of 12.57 and $13.36 \mathrm{~K}$.

of the expected spin-only value of $R \ln 6=3.56 \mathrm{cal}_{\mathrm{th}} \mathrm{K}^{-1} \mathrm{~mol}^{-1}$ for an $s=5 / 2$ system. The discrepancy is well within the uncertainty occasioned in the lattice estimate and the heat capacity extrapolated below $4 \mathrm{~K}$. Short-range ordering accounts for 28 per cent of the entropy above the $13.36 \mathrm{~K}$ peak.

To estimate the entropy increment below $4 \mathrm{~K}$ the magnetic heat capacity from 4 to $11.5 \mathrm{~K}$ (excluding the region near the $6.8 \mathrm{~K}$ peak) was fit to a power-law dependence $C_{\text {mag }}=A(T / \mathrm{K})^{B}$, with $A=0.052 \mathrm{cal}_{\mathrm{th}} \mathrm{K}^{-1} \mathrm{~mol}^{-1}, B=1.734$ (see figure 6). This power-law dependence was extrapolated to $T \rightarrow 0$ and the entropy increment calculated. The entropy below $4 \mathrm{~K}$ amounts to about 8 per cent of the total magnetic entropy. The coefficient $B$ is much closer to the value $3 / 2$ expected for ferromagnetic spin waves than for the cubic dependence of an antiferromagnetic substance such as $\mathrm{NiWO}_{4}$ or $\mathrm{CoWO}_{4}{ }^{(3)}$ However, since no theoretical work has been reported for the magnetic spectra of such a complex spin system, no interpretation can be given for $B$.

From figure 6 it will be seen also that the small peak at $6.80 \mathrm{~K}$ is but a small increment to the main power-law dependence and contributes only $0.01 \mathrm{cal}_{\mathrm{th}} \mathrm{K}^{-1}$ $\mathrm{mol}^{-1}$ to the magnetic entropy. These reasons, together with the observation that no anomaly is seen in the susceptibilities ${ }^{(10,12)}$ near $7 \mathrm{~K}$, argue against interpreting the heat-capacity peak at $6.8 \mathrm{~K}$ as a magnetic transition. 


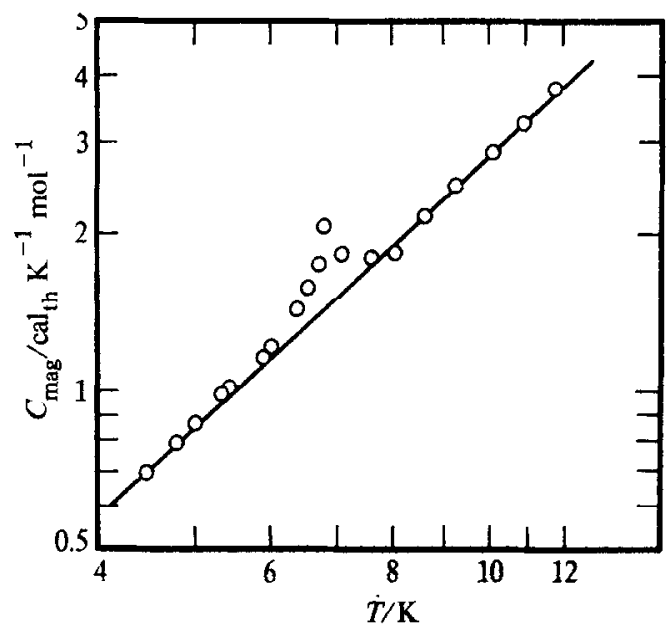

FIGURE 6. Exponential fit to heat capacity below $11.5 \mathrm{~K}$. The solid line represents the equation referred to in the text.

\section{MULTIPLE TRANSITIONS IN MANGANESE TUNGSTATE}

Can the double peak in $\mathrm{MnWO}_{4}$ be attributed to characteristics of the particular sample measured or is this behavior a property of manganese tungstate? Magnetic transitions can be affected by defects of the material such as strains, non-crystallinity, random impurities, lattice defects, grain growth, etc. These defects tend to lower and broaden the heat capacity peak. Hence, if the peak at $13.36 \mathrm{~K}$ is the "true" Néel temperature, the $12.57 \mathrm{~K}$ peak might be the maximum affected by imperfections. But this lower peak is as sharp as and even higher than the $13.36 \mathrm{~K}$ peak, leading to the conclusion that it has not been lowered by imperfections. Weitzel's discoveries ${ }^{(12,22)}$ on the properties of $(\mathrm{Mn}, \mathrm{Fe}) \mathrm{WO}_{4}$ lead to the suspicion that the high-temperature peak was displaced upwards in temperature due to the formation of $\mathrm{FeWO}_{4}$-type magnetic order within the sample. From Weitzel's data, ${ }^{(12)}$ a shift in the Néel temperature of $0.79 \mathrm{~K}$ would require a composition of $\left(\mathrm{Mn}_{0.93} \mathrm{Fe}_{0.07}\right) \mathrm{WO}_{4}$. The spectroscopic determination for iron revealed a mass fraction of only $4 \times 10^{-5}$ of iron in the sample, more than a thousand times below the required level. Hence, the double anomaly in $\mathrm{MnWO}_{4}$ is considered to be characteristic of the compound.

Multiple transitions have previously been seen in the low-temperature heatcapacity studies by Murray ${ }^{(23)}$ in $\mathrm{MnCl}_{2}$ in which twin peaks were found at 1.81 and $1.96 \mathrm{~K}$. Neutron-diffraction experiments ${ }^{(24)}$ revealed $\mathrm{MnCl}_{2}$ changes from a lowest temperature antiferromagnetic phase AFM-I to a higher antiferromagnetic phase AFM-II at $1.81 \mathrm{~K}$ and then becomes paramagnetic at $1.96 \mathrm{~K}$.

The tungstates have important similarities to the dichloride. Both structures consist of metals occupying octahedral holes in closest-packed lattices of anions. ${ }^{(25)}$ In such structures the nearest-neighbor $M-M$ exchange is with an anion at $90^{\circ}$. The problem of exchange in the tungstates was first treated by Van Uitert et al..$^{(10)}$ For $90^{\circ}$ superexchange Goodenough ${ }^{(26)}$ has predicted ferromagnetic coupling for 
$\mathrm{Fe}^{2+}, \mathrm{Co}^{2+}$, and $\mathrm{Ni}^{2+}$, and antiferromagnetic coupling for $\mathrm{Mn}^{2+}$. Such ferromagnetic alignment is observed in the iron, cobalt, and nickel dichlorides. The spins are arranged in ferromagnetic layers with adjacent layers aligned antiferromagnetically. ${ }^{(27)}$ As discussed in the introduction, this is also the spin arrangement of the $\mathrm{Fe}, \mathrm{Co}$, and $\mathrm{Ni}$ tungstates. In $\mathrm{MnCl}_{2}$, the spins do not order ferromagnetically within each layer but display a more complicated arrangement, ${ }^{(24)}$ similar to that for $\mathrm{MnWO}_{4}$. Moreover, recent work ${ }^{(28)}$ has revealed the presence of multiple lowtemperature magnetic phases in $\mathrm{MnBr}_{2}$, which shares closest packing and $90^{\circ}-n n$ superexchange with $\mathrm{MnCl}_{2}$.

Since the $\mathrm{MnWO}_{4}$ shares $90^{\circ}$ superexchange properties with $\mathrm{MnCl}_{2}$ and $\mathrm{MnBr}_{2}$, the twin-peaks near $13 \mathrm{~K}$ in the low-temperature heat capacity of $\mathrm{MnWO}_{4}$ are considered to be indicative of several magnetic changes of state.

The authors acknowledge with gratitude the partial financial support of this research endeavor by the Chemical Thermodynamics Program of the Chemistry Division of the National Science Foundation, as well as helpful discussions with Professor B. J. Evans and Dr William G. Lyon.

\section{REFERENCES}

1. Lyon, W. G; Westrum, E. F., Jr. J. Chem. Thermodynamics 1974, 6, 763.

2. Landee, C. P.; Westrum, E. F., Jr., J. Chem. Thermodynamics 1975, 7, 973

3. Landee, C. P.; Westrum, E. F., Jr. J. Chem. Thermodynamics (In press) (M-591).

4. Keeling, R. O. Acta Cryst. 1957, 10, 209.

5. Sleight, A. W. Acta Cryst. Section B 1972, 28, 2899.

6. Ulkü, D. Zeit. Krist. 1967, 124, 192

7. Weitzel, H. Solid State Commun. 1970, 8, 2071.

8. Dachs, H.; Weitzel, H.; Stoll, E. Solid State Commun. 1966, 4, 473; Dachs, H.; Stoll, E.; Weitzel, H. Zeit. Krist, 1967, 125, 120.

9. Dachs, H. Solid State Commun. 1969, 7, 1015.

10. Van Uitert, L. G.; Sherwood, R. C.; Williams, H. J.; Rubin, J. J. ; Bonner, W. A. J. Phys. Chem. Solids 1964, 25, 1447.

11. Shapovalova, R. D.; Belova, V. I.; Zalesskii, A. V.; Gerasimov, Ya. I. Russ. J. Phys. Chem. 1961, 35, 1340.

12. Weitzel, H. Solid State Commun. 1969, 7, 1249; Neus Jb. Miner. Abh. 1970, 113, 13.

13. Broch, E. K. Norske Videnskaps-Acad. Skriften I. 1929, No. 8, pp. 61.

14. Swanson, H. E.; Morris, M. C.; Stinchfield, R. P.; Evans, E. E. Nat. Bur. Stand. (U.S.), Monogr. 26, Sec 6.2, 1963.

15. Sasaki, A. Mineral J. 1959, 2, 375.

16. Landee, C. P., Ph.D. Thesis, The University of Michigan, Ann Arbor, Michigan 1975. Diss. Abstr., 1975, 36, 06, 2828-B. Detailed supplementary information on X-ray structural patterns for some samples and detailed thermodynamic functions for all samples are presented in NAPS document No. 02765 for 22 pages of supplementary materials. Order from ASIS/NAPS c/o Microfiche Publications, 440 Park Avenue South, New York, N.Y. 10016 U.S.A. Remit in advance for each NAPS accession number. Make checks payable to Microfiche Publications. Photocopies are \$5.50. Microfiche are \$3.00. Outside of the U.S. and Canada, postage is $\$ 2.00$ for a photocopy or $\$ 1.00$ for a fiche.

17. Schwartzkopf Microanalytical Laboratories, Woodside, New York.

18. Gottschalk, G. Z. Anal. Chem. 1962, 187, 164.

19. Westrum, E. F., Jr.; Furukawa, G. T.; McCullough, J. P. Adiabatic low-temperature calorimetry. In Experimentsl Thermodynamics, Vol. 1, McCullough, J. P.; Scott, D. W.; editors. Butterworths: London, 1968.

20. Lesne, H. P.; Caillet, P. Can. J. Spectrosc. 1973, 18, 69. 
21. Mannheim, P. D.; Simpoulos, A. Phys. Rev. 1968, 165, 845; Nussbaum, R. H.; Howard, P. G.; Lees, W. L.; Steen, C. F. Phys. Rev. 1968, 173, 653.

22 Weitzel, H. Zeit. Krist. 1970, 131, 289.

23 Murray, R. B. Phys. Rev. 1962, 128, 1570.

24 Wilkinson, M. K.; Cable, J. W.; Wollan, E. O.; Koehler, W. C. Oak Ridge National Laboratory Report ORNL-2501, 1958, unpublished, Oak Ridge National Laboratory Report ORNL-2430, 1958, unpublished.

25. Grime, H.; Santos, J. A. Kristallog. 1934, 88, 136.

26. Goodenough, J. B. Magnetism and the Chemical Bond. Interscience: New York, 1963.

27. Wilkinson, M. K.; Cable, J. W.; Wollan, E. O.; Koehler, W. C. Phys. Rev. 1959, 113 , 497.

28. Regis, M.; Farge, Y.; Royce, B. S. H. AIP Conference Proceedings. "Magnetism and Magnetic Materials-1975". (In press). 